\title{
Erratum to: Hyperglycemia promotes p53-Mdm2 interaction but reduces p53 ubiquitination in RINm5F cells
}

\author{
R. Barzalobre-Gerónimo ${ }^{1,2}$ - L. A. Flores-López ${ }^{1}$ L. A. Baiza-Gutman ${ }^{3}$. \\ M. Cruz ${ }^{1} \cdot$ R. García-Macedo ${ }^{1}$ - A. Ávalos-Rodríguez ${ }^{4}$ A. Contreras-Ramos ${ }^{5}$. \\ M. Díaz-Flores ${ }^{1}$ C. Ortega-Camarillo ${ }^{1}$
}

Published online: 31 May 2015

(c) Springer Science+Business Media New York 2015

\section{Erratum to: Mol Cell Biochem (2015) 405:257-264 DOI 10.1007/s11010-015-2416-0}

In the original article the authors appear with full first names and the last name only with initials. This is not correct. The author's names should have appeared as follows:
R. Barzalobre-Gerónimo, L. A. Flores-López, L. A. Baiza-Gutman, M. Cruz, R. García-Macedo, A. ÁvalosRodríguez, A. Contreras-Ramos, M. Díaz-Flores, C. Ortega Camarillo

Everything else in the paper remains correct.

The online version of the original article can be found under doi:10.1007/s11010-015-2416-0.

C. Ortega-Camarillo

cocamarillo2014@gmail.com

1 Unidad de Investigación Médica en Bioquímica, HE, Centro Médico Nacional Siglo XXI, IMSS, Av Cuauhtémoc $330 \mathrm{Col}$ Doctores, Del. Cuauhtémoc, C.P. 06720, Mexico, DF, Mexico

2 Posgrado en Ciencias Biológicas, Universidad Nacional Autónoma de México, Edificio B, 1er. Piso, Circuito de Posgrados Cd. Universitaria. Del. Coyoacán, C.P. 04510, México, DF, México

3 Laboratorio en Biología del Desarrollo. Unidad de Morfología FES-Iztacala, UNAM, Av. de los Barrios 1, Los Reyes Iztacala, C.P. 54090, Tlanepantla, Edo. de México, Mexico

4 Bioquímica de la Reproducción, Depto. Prod. Agrícola y Animal, Universidad Autónoma Metropolitana-Xoch, Calz del Hueso 1100, Col. Villa Quietud, Del. Coyoacán, C.P. 04960, México, DF, México

5 Lab. de Biología del Desarrollo y T. Exp, Hospital Infantil de Mexico Federico Gomez, Dr. Marquez 162, Col Doctores Del. Cuauhtémoc, C.P. 06720, México, DF, México 